Katrin König

\title{
Begnadete Freiheit
}

Anselm von Canterburys Freiheitstheorie

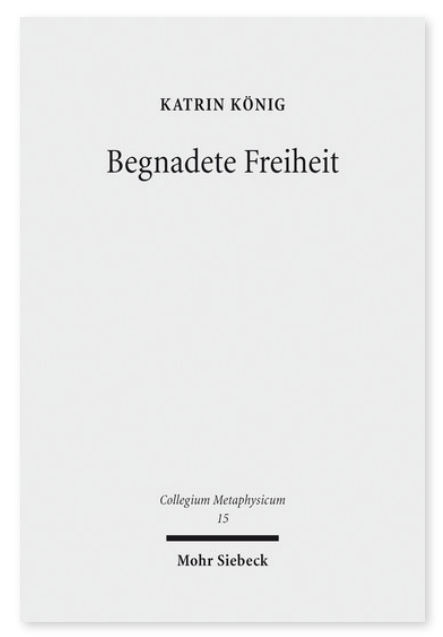

2016. XII, 382 Seiten. CM 15

ISBN 978-3-16-154385-2

DOI 10.1628/978-3-16-154385-2

eBook PDF 79,00€

ISBN 978-3-16-154384-5

fadengeheftete Broschur 79,00€
Was ist Freiheit? Ist der Mensch frei? Und: Sind Gott und menschliche Freiheit vereinbar? Diese Fragen untersucht Anselm von Canterbury in seinen Freiheitsdialogen.

Katrin König deutet Anselms Freiheitstheorie in ihrem theologischen Zusammenhang, verortet sie historisch und bringt sie ins Gespräch mit analytisch-philosophischen Freiheitstheorien der Gegenwart. Damit wird ein qualitativer Begriff von Freiheit als Gabe zum Guten zur Diskussion gestellt: begnadete Freiheit. Freiheit ist diesem Verständnis nach mehr als individuelle Selbstbestimmung oder Wahl zwischen alternativen Möglichkeiten. Sie gründet in Wahrheitserkenntnis, entfaltet sich in Gerechtigkeitsliebe und ist mit vollkommener Bestimmtheit durch das Wirken Gottes vereinbar. In diesem Horizont können Aporien der modernen Determinismusdebatte wahrgenommen und scheinbare Gegensätze vermittelt werden. Diese Arbeit wurde mit dem Manfred Lautenschlaeger Award for Theological Promise 2017 ausgezeichnet.

Katrin König 2003-10 Studium der Ev. Theologie und Philosophie; 2013 Promotion; 2013-16 Vikariat, Ordination und Pfarrdienst in der Evangelischen Landeskirche in Baden; 2016-18 Theologische Mitarbeiterin des Landesbischofs; 2017-19 Wissenschaftliche Assistentin an der Universität Tübingen; seit 2019 Studienleiterin am Theologischen Studienhaus im Morata-Haus und Lehrbeauftragte und Habilitandin am Ökumenischen Institut an der Universität Heidelberg.

Jetzt bestellen:

https://mohrsiebeck.com/buch/begnadete-freiheit-9783161543852?no_cache=1

order@mohrsiebeck.com

Telefon: +49 (0)7071-923-17

Telefax: +49 (0)7071-51104 